\title{
Scrutinizing Algerian EFL students' challenges in research teaching and writing
}

\author{
CHAHRAZED HAMZAOUI*
}

Belhadj Bouchaib University, Ain-Temouchent, Algeria

\section{RESEARCH ARTICLE}

Received: March 9, 2021 • Accepted: July 6, 2021

Published online: September 24, 2021

(C) 2021 The Author(s)

\begin{abstract}
Writing to report research writing may be a daunting task since it requires motivation, interest, background knowledge and hard work from the part of students. This paper focused on the major obstacles faced by the English foreign language learners in research writing at Belhadj Bouchaib University, Algeria, in addition to the teachers' attitudes towards their students' work. The study relied on a triangulated approach which enclosed quantitative and qualitative methods and its importance lied in providing insights into the nature of flaws and challenges as regards students' academic writing practices. A questionnaire was used among 30 students followed by an interview with six teachers. The findings revealed that developing a research project and reporting the findings were among the most difficult challenges encountered by the learners. While the former requires them to identify the area of interest, choose a topic and formulate a researchable problem, the latter typically entails writing the methodology, results, and discussion sections. Between the two tasks, the students found academic writing the most challenging. The findings also revealed that teachers display negative attitudes towards their students' research because of these reasons: lack of motivation following traditional methods of learning, insufficient background knowledge about research, paucity of library resources, sketchy number of courses related to research, and the unavailability of the Internet inside the university context. Following these flaws, some recommendations were provided.
\end{abstract}

\section{KEYWORDS}

Algerian EFL students, Belhadj Bouchaib university research challenges, research teaching, research writing

\footnotetext{
*Corresponding author. Email: chahrazed_hamzaoui@yahoo.fr
} 


\section{INTRODUCTION}

Research writing is a daunting task for most Algerian English foreign language (EFL)students since it requires from them the capability to have various strenuous skills like selecting a topic, planning, doing research, critical thinking, the correct use of language (grammar, choice of words, etc.) and style, to mention a few. Therefore, they have to cope with and may encounter many challenges especially while starting to deal with research and writing for the first time. This process renders this academic mission even more problematic. Todd, Smith, and Bannister (2006) believe that whenever a new approach to learning is introduced, it is considered troubling and disturbing for students who will surely encounter challenges when starting to write independently their first piece of paper. (Table 1)

In the Algerian context, thesis writing is a mandatory academic task and a significant process for EFL Master students during their second year of Postgraduate level, a challenging task that reports on a research project and entails not only writing per se but also requires extensive learning and reading during and before the writing process. Exploring such an issue can help

Table 1. EFL Students' Challenges in Research Writing

\begin{tabular}{|c|c|c|c|c|c|}
\hline \multirow[b]{2}{*}{ Items } & \multirow[b]{2}{*}{ Statements } & \multicolumn{4}{|c|}{ Alternatives (\%) } \\
\hline & & $\mathrm{SD}$ & $\mathrm{D}$ & A & SA \\
\hline 1 & $\begin{array}{l}\text { Selecting a topic of research is not an } \\
\text { easy task }\end{array}$ & 19 & 25 & 55 & 1 \\
\hline 2 & $\begin{array}{l}\text { I find difficulty to distinguish between } \\
\text { formal and non-formal writing }\end{array}$ & 10 & 30 & 60 & - \\
\hline 3 & $\begin{array}{l}\text { I find difficulty in selecting the words to } \\
\text { convey the idea to the readers. }\end{array}$ & - & 35 & 65 & - \\
\hline 4 & $\begin{array}{l}\text { I find it difficult to use good English } \\
\text { grammar }\end{array}$ & 5 & 30 & 60 & 5 \\
\hline 5 & $\begin{array}{c}\text { It is hard to organize my idea/opinion } \\
\text { in paragraph }\end{array}$ & 4 & 25 & 55 & 16 \\
\hline 6 & $\begin{array}{l}\text { I have difficulty in summarizing and } \\
\text { paraphrasing author's ideas }\end{array}$ & 3 & 10 & 70 & 17 \\
\hline 7 & $\begin{array}{l}\text { Using my own words is a challenging } \\
\text { task to me }\end{array}$ & - & 10 & 65 & 25 \\
\hline 8 & $\begin{array}{l}\text { I have difficulty in writing literature } \\
\text { review }\end{array}$ & 2 & 8 & 54 & 36 \\
\hline 9 & $\begin{array}{l}\text { Selecting the sample of the research is } \\
\text { an arduous task }\end{array}$ & - & 20 & 60 & 20 \\
\hline 10 & $\begin{array}{l}\text { It is difficult to find appropriate sources } \\
\text { for the research }\end{array}$ & 5 & 50 & 30 & 15 \\
\hline 11 & $\begin{array}{l}\text { It is hard to cite correctly the references } \\
\text { used in my study }\end{array}$ & 6 & 65 & 20 & 9 \\
\hline 12 & $\begin{array}{l}\text { The subjects we studied in our master } \\
\text { programmes had not prepared us to } \\
\text { write the Master thesis }\end{array}$ & - & 5 & 80 & 15 \\
\hline
\end{tabular}


identify the major difficulties which impede students from conducting good research, guide how to deal with these difficulties, and generate solutions to overcome these flaws.

In terms of research writing, most learners find it challenging to connect and organize ideas, and write using their own words. The main purpose of the present study is to obtain a perspective with regard the main flaws and challenges faced by EFL learners in research writing at Belhadj Bouchaib University, as well as teachers' attitudes towards their students' work. This purpose is considered crucial as the challenges are omnipresent and multifaceted. And since thesis writing is part of Master two EFL students' academic career in the Algerian context, this study attempts to fill an important research gap by investigating the flaws and challenges facing EFL students in the course of writing their thesis, taking into consideration the difficulties in producing the thesis text and the teachers' attitudes towards their students' work. Therefore, this study has been guided by the following research questions:

1. What challenges do EFL learners encounter in research writing?

2. What attitudes do teachers display towards their students' work?

3. Which measures should be undertaken to alleviate the challenges?

And thus, its objectives are threefold: (1) to identify the challenges that EFL learners encounter in research writing. (2) to detect teachers' attitudes towards their students' work. (3) to disclose solutions to mitigate the flaws.

\section{LITERATURE REVIEW}

Research writing remains a prominent issue for students, especially for those involved in the process of writing a thesis academically. According to Fukao and Fujii (2001), academic writing requires learners to have the ability to integrate skills that encompass gathering information, organizing ideas in a logical order, summarizing resources, paraphrasing, editing, and final proofreading. The available literature indicates that a good number of studies have been conducted worldwide on either postgraduate supervision or thesis writing challenges. Irvin (2010) defined academic writing as a form "of evaluation that requires students to demonstrate knowledge and show proficiency with certain disciplinary skills of thinking, interpreting, and presenting" (p. 8). In terms of clarity and conciseness, Turner (2011) mentions that "tightly ordered logical exposition, concision in choice of lexis, clarity, and economy of style continue to be the rhetorical norms within which academic writing pedagogy and expectations of a smooth read, operate" (p. 78). Bitchener and Basturkmen (2006) have depicted the learners' flaws in writing research and stressed obstacles with the language and the way to express and connect ideas. They also recognized that these obstacles sometimes go beyond the designated time provided for carrying out the research. Moreover, Bitchener and Basturkmen (2006), Ho (2013), Singh (2015), and Komba (2015) have found that students encountered difficulty in structuring the constituent parts of the thesis.

The accessible literature shows that some students, who are required to write a thesis in English either as a foreign or a second language, still struggle with more credible linguistic problems such as difficulties with grammar and punctuation and limitation in vocabulary to express ideas and views (Alsied \& Ibrahim, 2017; Chang \& Strauss, 2010; Singh, 2015; Strauss, 2012). As an illustration, Alsied \& Ibrahim (2017) surveyed challenges in research writing from 
Libyan EFL undergraduate students' and their teachers' perspectives selecting a sample encompassing 42 EFL students and 4 teachers who were chosen from a Libyan state university. The findings of the study showed that EFL students encountered obstacles either in the research stage or in the thesis writing process. Mainly, they perceived the tasks of identifying the area of interest, choosing a topic, formulating research problems, and writing a literature review as highly problematic. Besides, other challenges were faced such as problems in collecting and analyzing data, ineffective background knowledge about research, paucity of motivation, and paucity of resources in the library.

Following the same interest, and in a study conducted by Bitchener and Basturkmen (2006) which emphasized students' flaws in writing the discussion of the results section of the thesis, the results revealed that students did not have an appropriate comprehension of the function of the discussion results sections of their thesis. Moreover, and in a more recent study carried out by Alshehry (2014) to explore the challenges that female undergraduate students and their teachers encounter at Najran University in Saudi Arabia, using a semi-structured interview with twenty students and four lecturers as a tool of research.

The results showed that students encountered significant flaws consisting in looking for resources, time, and creative procedures. The results also revealed that students faced problems in research writing such as having no time to conduct research and issues related to ethics. Another great difficulty lied in the students' lack of experience and knowledge about research, and the difficulty to decide on convenient topics with appropriate references. Moreover, they had problems finding libraries where they can search for books. Students in some towns had a very weak internet connection and some needful books were not available in the library. Regarding the students' knowledge and experience about research, teachers identified that most learners had no idea of how to search for information on their own. "Furthermore, research has found that one of the setbacks of lacking in English language proficiency is the negative impact on students' academic writing practices which had directly affected their academic success" (Singh, 2017, p. 623).

Divsar (2018), for his part, carried out a study consisting of the challenges encountered by Iranian TEFL students in thesis writing. The findings of this study showed that linguistic problems, including grammatical and organizational problems and lack of mastery of academic writing style, were among the dominant obstacles faced by Iranian EFL students. However, findings showed that the students reported a wide range of other difficulties which were grouped into three main categories: (i) instructional and pedagogical inadequacies (mainly students' lack of knowledge and experience in researching and writing up their thesis), (ii) personal problems and affairs such as poor management of time and the loss of interest and motivation in the process of thesis writing, and (iii) educational support such as the limited availability and assistance offered by the supervisor and adviser. In a more recent study conducted by Boufeldja and Bouhania, (2020) where they explored the difficulties faced by Algerian EFL Master students in the process of writing their thesis, from their own as well as their supervisors' perspectives, the findings of the study revealed that Algerian EFL students perceived linguistic problems as less problematic than sociocultural challenges. The sociocultural challenges include Inadequate supports and cooperation, poor-quality academic preparation: education, students' lack of preparedness, insufficient academic writing skills, and lack of research skills and knowledge. According to Boufeldja and Bouhania (2020), 
Apart from the generic and rhetorical challenges, the literature, on the other hand, shows that some students, who have to write a thesis in English as a foreign or as a second language, still struggle with more palpable linguistic difficulties such as problems with grammar and punctuation and limitation in vocabulary to express ideas and views (p. 2245).

Results from the above-cited studies propose that EFL students do not just encounter obstacles in writing per se, but they also have to cope with personal and social challenges and problems in the whole process of writing their thesis. However, most of the studies have been conducted in either developed countries or elsewhere outside Algeria, and limited studies are available as far as the Algerian context is concerned. The current study focuses on the obstructions in carrying out research writing among Algerian EFL Master students at Belhadj Bouchaib University. Albeit this is a major issue, no great attention has been paid to tackle such challenges so far and that is why this study was carried out. Therefore, there is a need to do more research on this issue.

\section{METHODS}

\section{Participants}

This study used purposive sampling with the aim of selecting all accessible participants who could provide appropriate and reliable information regarding the research problem. This is because purposive sampling entails choosing a sample that yields the most comprehensive understanding in the form of rich information on the topic. The participants consisted of 30 students and six teachers who were selected from the Department of English, Belhadj Bouchaib University, Algeria. Those students were in their Master two level and they had almost finished writing their thesis. They were 22 females and 8 males and their ages ranged between 23 and 35 . Among the selected teachers, there were four females and two males whose teaching and supervising experience with EFL Master students ranged between seven to 11 years. The teachers were selected using purposive sampling because these were expected to give valuable and richer information for the study than any new university teacher.

\section{Research instruments}

This study used two different research instruments: a Likert scale questionnaire that was measured on a four-point Likert scale including 12 items to obtain the participants' level agreement which is as follows: strongly disagree, disagree, strongly agree and agree, and a semi structured interview.

\section{Data collection procedures}

The Likert scale questionnaire was delivered for the students who took part in it to get their views and know more about the challenges encountered in research writing's conduct. An appointment was made with the teachers to allow the researcher administer the questionnaire to the students. Subsequently, the researchers met the students and the aim of the study was explained to them. Then the questionnaire was distributed to them at class time and they took 15 min to complete it. 
Additionally, a semi-structured interview was conducted in English with six teachers to find out about their attitudes towards their students' work. The participants were informed of the aim of the interview and were interviewed in person out of class sessions, and it took $15 \mathrm{~min}$ with each participant. After asking permission from the respondents, the interviews were audiorecorded and transcribed. These participants had experience of supervision ranging from 6 to 15 years.

\section{Data presentation}

The questionnaire. This section is completely devoted to the presentation of the results obtained from the Likert scale questionnaire administered to the students whose major aim was to explore the difficulty and challenges faced in research writing.

The interview. The interview is semi-structured and aims at detecting the teachers' attitudes towards their students' work. It was conducted with the teachers being in charge of different subjects at the department of English and then analyzed qualitatively.

Q1. Are your students motivated to do research?

All teachers provided a positive answer stating that 'our students are discouraged because of the following reasons: absence of any background knowledge about research, lack of knowledge about what constitutes research and how to do it, and their disability to select a topic'.

Q2. What reasons stand behind the students' lack of proficiency in research writing?

A teacher of ten years of teaching experience said 'Students are victims of a system of education that does not provide them with the necessary equipment to get started for writing a thesis; they are unable to analyze data both qualitatively and qualitatively, unable to choose an adequate sampling and even unaware of what makes a good research work!'. Another teacher reported the following: 'I relate this problem to several factors, such as lack of practicality, lack of resources, lack of background knowledge about doing research, lack of reading, poor academic writing and these are enough not to develop strong researchers'.

Q3. Does the academic atmosphere help in motivating students to write research?

When this question was posed, four teachers said, 'the academic atmosphere does not help in motivating students to conduct and write research due to a lack of resources, not studying statistics to analyze quantitative data not having lectures for analyzing qualitative data and subjects are taught theoretically'. To this, they added, 'there is lack of practice, absence of laboratories in the department, the restricted number of classes and lecture halls which does not match with the number of students enrolled, in addition to students who scarcely work together in groups to exchange ideas and discuss different topics'. Two others teachers mentioned the following, 'we should include the subjects of research methodology and academic writing starting from the first year to facilitate the task of writing research years later for both partner parties that is teachers and students'.

Q4. What are the main challenges that you face as supervisors?

Here are some of the participants' replies: 
'time is a great challenge, for we supervise five or six students at the same time'; they also claimed that 'students are lazy, not motivated and plagiarise whole paragraphs'.

'students do not do the necessary corrections the way their supervisor asks them to do; students are lazy and unmotivated; most of them plagiarize whole paragraphs and copy from others' work'.

Q5. Are there other challenges?

The participants pointed out to the following challenges:

- Bad internet connection, poor writing, lack of contact with the supervisor, not being regularly in contact with the supervisor, lack of competence in grammar and punctuation, poor organizational skills, and the students who write the way they think.

\section{DISCUSSION}

This section discusses and interprets the findings obtained from the research tools used. Based on the elaboration of the results obtained from the Likert scale questionnaire, it could be discussed that there are several challenges encountered by the students in research writing; for example, the majority of students (55\%) agreed that they face difficulties as to the choice of the accurate topic of research. This seems to corroborate with Alsied and Ibrahim (2017) findings. Evidence from the results is the daunting task of distinguishing between formal and non-formal writing since $60 \%$ reported on this. The students had to write their thesis with insufficient academic writing. This is mainly due to the lack of academic writing practice. As Komba (2015) has proposed, university teachers are advised to revise the teaching methods and the contents of academic writing and methodology modules to make them cope with the needs of EFL students to accomplish the writing of the thesis.

Besides, selecting appropriate words to convey ideas is also considered challenging, for most students since $65 \%$ agreed with this statement. Grammar is also identified as a problem encountered by the students $(60 \%)$ in this study whereas a minority of students disagreed (35\%). These kind of difficulties have already been reported by Alsied and Ibrahim, 2017; Chang \& Strauss, 2010; Singh, 2015; Strauss, 2012). The textual organization is another challenge where the students get stuck on how their idea is organized. In other words, the students find difficulty on how to organize and develop their idea in an ordered way (Cargill and O'Connor, 2009). When it comes to paraphrasing and summarizing authors' ideas, this task is also arduous for the vast majority of the students (70\%). They also pointed out their disability to use their own words. As a result, this can reflect negatively on the process of research writing.

The participants reported problems related to research methodology. As can be seen in table one, writing a literature review and selecting the sample of the research is quite difficult for most of them (54-60\%). This corresponds with Alsied and Ibrahim (2017) findings where they reported that writing the literature review is a daunting task for students. The teaching commitments for some teachers may have contributed to the problem of the research writing as well since the majority of students $(80 \%)$ reported their dissatisfaction with the teaching they received in the courses and subjects they studied in their Master programmes, noting that the subject of research methodology is taught for one semester at Master two level. 
However, surprisingly, difficulties such as finding appropriate sources for the research and accurately cite the references used in their study were rejected by the participants. The students find it easy as to how they cite and make references. This can be explained by the fact that these students have already been acquainted with such an activity.

As far as the interview's findings are concerned, The teachers' judgments are highly supported by the results of a study conducted by Mahammoda (2016) which demonstrated that Ethiopian university students do not have any motivation in the topic of research which influences the research quality and makes it hard for them to do good quality research. Also, all the respondents stressed their students' lack of preparedness for such a task. Being prepared for thesis writing requires that students must wield an extensive range of skills, encompassing appropriate knowledge of how to select a topic of research, undertake research and write up the various chapters of the thesis. Nevertheless, it was alarming that the teachers who also play the role of supervisors reported the students' lack of the skills necessary for researching and writing up the Master thesis. This is highly supported by Alshery's (2014) conducted study where he opined that the teachers found that their students had no idea on how to search for information on their own.

When asked about the reasons that stand behind the students' lack of proficiency in research writing, the teachers' respondents pointed out the poor-quality education through the Master level, in addition to some lacunae related to the methodological ground such as the students' lack of knowledge with regard to the APA and MLA referencing styles. They also opined that the students were taught the subject of methodology by a part-time teacher who might not be able to provide them with good quality instruction.

When asked whether or not the academic atmosphere helps in motivating the students to write research, four teachers agreed that the academic atmosphere does not aid in motivating students to conduct and write research because of various reasons, among these reasons, there is a lack of resources, not studying statistics to analyze quantitative data, not having lectures for analyzing qualitative data, subjects are only taught theoretically; there is lack of practice, absence of laboratories in the department, the restricted number of classes and lecture halls which does not match with the number of students enrolled, in addition to students who scarcely work together in groups to exchange ideas and discuss different topics. A quite interesting idea was suggested by the two others teachers who proposed to include the subjects of research methodology and academic writing starting from the first year to facilitate the task of writing research years later for both partner parties that is teachers and students.

In terms of the challenges that the teachers encountered as supervisors, here again, teachers opined that several factors come into play such as time, students' laziness and plagiarism. Work in tandem was another challenge where the students are not regularly in contact with each other. Challenges also consisted in the students who do not do the necessary corrections the way their supervisor asked them to do, in addition to the lack of motivation. Other challenges related to the bad internet connection, the students' writing which is poor, and not being regularly in contact with the supervisor.

When asked whether or not there are other challenges to report about, it seemed like if the teachers did not say much about their students' work; three of them pointed out that the students show incompetence in the use of grammar and punctuation especially the use of tenses, commas, and semi-colons, though they have been taught these lessons starting from 
the first year at university. Still, another teacher claimed that they think in their mother tongue and write in English, in addition to poor organizational skills. The linguistic problems tie with (Alsied \& Ibrahim, 2017; Boufeldja \& Bouhania, 2020; Chang \& Strauss, 2010; Singh, 2015, 2017; Strauss, 2012) findings where lack in English proficiency may affect students' academic success. The poor academic writing obstacles are what Boufeldja \& Bouhania (2020) considered sociocultural factors. The use of abbreviations, lack of unity and coherence, and sentence structure are also among the other challenges encountered by the teachers. Indeed, most of these challenges, especially those related to poor academic writing, topic choice, bad grammar, and lack of methodological conventions have been reported by the students themselves.

\section{CONCLUSIONS AND RECOMMENDATIONS}

As the aim of this study has been to identify the major obstacles faced by EFL learners in research writing at Belhadj Bouchaib University, Algeria, in addition to teachers' attitudes towards their students' work, the identification of those challenges has been successfully achieved using both quantitative and qualitative approaches. The results revealed that Algerian EFL learners have difficulty in selecting a topic of research, writing a literature review, paraphrasing, and differentiating between formal and non-formal English. They also lack preparedness; their academic writing is very weak, along with the most challenging obstacle being research writing. Consequently, those learners will yield very poor-quality research. Moreover, teachers displayed negative attitudes towards their students' work because of various factors, some of which were lack of motivation, poor academic writing, lack of background knowledge about what constitutes research, bad Internet connection, students' laziness, etc. After the exegesis of the findings of the current study, it can be deduced that Algerian EFL students face a lot of shortcomings in research because they are unaware of the significance of undertaking research, and not sufficiently prepared for this daunting and laborious task.

It is worth noting that research writing is not an easy task. It is essentially the product of effective training and proper guidance. Given the observed challenges, the following recommendations are made: First, the Algerian universities should strive to subject all Master two students to academic writing training with a special emphasis on how to write research projects and theses. It is recommended that more emphasis should be given to the investigation of difficulties of research writing to find out the area of research in which students have lacunae. Second, teachers must encourage their students to read extensively to enrich their knowledge and students should take intensive writing courses to aid them to write appropriately and correctly. Third, there is a need to review research methods courses offered in the Algerian universities, in terms of contents and teaching approaches.

If this is properly done, the lacunae indicated by candidates are likely to be minimized. Further research should also focus on a large number of participants to achieve generalization of the results and have a wider picture of research writing challenges in all Algerian universities. Future research can also be done to scrutinize the opinions of Doctoral EFL students about their thesis writing challenges to detect whether they encounter the same or disparate types of challenges. Finally, it is hoped that the results obtained from the current study will help teachers, 
practitioners, and curriculum designers develop their teaching methods about research and thesis writing.

\section{REFERENCES}

Alshehry, A. T. (2014). Teaching research writing to female undergraduates in Saudi Arabia. International Journal of Education Learning and Development, 2(4), 15-25.

Alsied, S. M., \& Ibrahim, N. W. (2017). Exploring challenges encountered by EFL Libyan learners in research teaching and writing. IAFOR Journal of Language Learning, 3(2), 143-160. Retrieved from https://doi.org/10.22492/ijll.3.2.06.

Bitchener, J., \& Basturkmen, H. (2006). Perceptions of the difficulties of postgraduate L2 thesis students writing the discussion section. Journal of English for Academic Purposes, 5(1), 4-18. Retrieved from https://doi.org/10.1016/j.jeap.2005.10.002.

Boufeldja, B., \& Bouhania, B. (2020). A qualitative inquiry into the difficulties experienced by Algerian EFL master students in thesis writing: 'Language is not the only problem. Arab World English Journal 11(2), 243-257. https://doi.org/10.24093/awej/vol11no2.17.

Cargill, M., \& O'Connor, P. (2009). Writing scientific research articles. UK: Wiley Blackwell.

Chang, C. E., \& Strauss, P. (2010). 'Active agents of change?' Mandarin-speaking students in New Zealand and the thesis writing process. Language and Education, 24(5), 415-429. https://doi.org/10.1080/ 09500781003789873.

Divsar, H. (2018). Exploring the challenges faced by Iranian TEFL students in their doctoral dissertation writing. International Journal of English Language and Translation Studies, 6(3), 195-203.

Fukao, A., \& Fujii, T. (2001). Investigating difficulties in the academic writing process: Interview as a research tool. ICU Language Research Bulletin, 16, 29-40.

Ho, M. C. (2013). The difficulties in disciplinary research writing: A case study of first year graduate students in Taiwan. Journal of Teaching and Teacher Education, 2(4), 77-87.

Irvin, L. L. (2010). What is "Academic Writing"? (Vol. 1). Library of Congress Cataloging-In-Publication Data Writing Spaces: Readings on Writing. edited by (Charles Lowe and Pavel Zemliansky).

Komba, S. C. (2015). Challenges of writing theses and dissertations among postgraduate students in Tanzanian higher learning institutions. International Journal of Research Studies in Education, 5(3), 71-80. https://doi.org/10.5861/ijrse.2015.1280.

Mahammoda, S. A. (2016). Factors affecting the quality of undergraduate research work in Bahir Dar University, Ethiopia. International Journal of Innovative Research and Development, 5(12), 23-27.

Singh, M. K. (2015). International graduate students' academic writing practices in Malaysia: Challenges and solutions. Journal of International Students, 5(1), 12-22.

Singh, M. K. (2017). International EFL/ESL master students' adaptation strategies for academic writing practices at tertiary level. Journal of International Students, 7(3), 620-643. https://doi.org/10.5281/ zenodo.570025.

Strauss, P. (2012). 'The English is not the same': Challenges in thesis writing for second language speakers of English. Teaching In Higher Education, 17(3), 283-293. https://doi.org/10.1080/13562517.2011. 611871. 
Todd, M. J., Smith, K., \& Bannister, P. (2006) Supervising a social science undergraduate dissertation: Staff experiences and perceptions. Teaching in Higher Education, 11(2), 161-173. Retrieved from https://doi. org/10.1080/13562510500527693.

Turner, J. (2011). Language in the academy.Cultural reflexivity and intercultural dynamics. Frankfurt Lodge: Clevedon Hall, (Victoria Road City, country: Multilingual Matters).

Open Access. This is an open-access article distributed under the terms of the Creative Commons Attribution-NonCommercial 4.0 International License (https://creativecommons.org/licenses/by-nc/4.0/), which permits unrestricted use, distribution, and reproduction in any medium for non-commercial purposes, provided the original author and source are credited, a link to the CC License is provided, and changes - if any - are indicated. 